\title{
A randomized controlled trial of different serum phosphate ranges in subjects on hemodialysis
}

Ramya Bhargava ${ }^{1 *}$ (D, Philip A. Kalra ${ }^{2}$, Mark Hann $^{3}$, Paul Brenchley ${ }^{4}$, Helen Hurst ${ }^{4}$ and Alastair J. Hutchison ${ }^{5,6}$

\begin{abstract}
Background: Hyperphosphataemia in dialysis subjects is associated with increased mortality. However cause and effect has not been proven, and the ideal phosphate target range is unknown despite KDOQI's call for studies over 12 years ago. The design and conduct of a randomized controlled trial is challenging because maintaining two groups within differing target ranges of serum phosphate has not been achieved over a long follow-up of 1 year, in a trial setting, before. The SPIRiT study examines the subject acceptance, recruitment and retention rates for such a study in which subjects were randomised to two distinct serum phosphate concentrations, then titrated and maintained over 12 months.

Methods: A two center trial of 104 hemodialysis subjects randomized to lower range LRG $0.8-1.4 \mathrm{mmol} / \mathrm{L}$ or $2.5-4.3 \mathrm{mg} / \mathrm{dL}$ ) and higher range (HRG $1.8-2.4 \mathrm{mmol} / \mathrm{L}$ or $5.6-7.4 \mathrm{mg} / \mathrm{dL}$ ) serum phosphate groups. Two months' titration and ten months' maintenance phase. Interventions were non-calcium phosphate binders, self-help questionnaires, with blood tests at specified time intervals.
\end{abstract}

Results: Thirteen percent of the eligible dialysis population were successfully recruited. A mean separation by serum phosphate of $1.1 \mathrm{mg} / \mathrm{dL}$ was achieved and maintained between the groups over 10 months. Drop-out rate was $27 \%$ with mortality $10 \%$. Nine subjects in the HRG (17.6\%) and two subjects in the LRG (3.8\%) died during the study, however the study was not powered to detect significant differences in outcomes.

Conclusion: Randomizing dialysis subjects to separate treatment targets for serum phosphate can achieve a clinically significant sustained separation over 12 months. A large scale longer term study is required to examine outcomes including mortality.

Trial registration: The trial registration number is ISRCTN24741445 - Date of registration 16th January, retrospectively registered.

Keywords: Hyperphosphatemia, Oral phosphate binders, Clinical trial, Dialysis, Mortality

\section{Background}

Large observational studies have identified hyperphosphatemia as an independent risk factor for cardiovascular disease and mortality in dialysis patients [1-3]. Such studies cannot establish causality, but current guidelines encourage careful control of serum phosphate in the uncertain expectation that it will improve outcomes. Studies of serum phosphate focus on licensing requirements for the binder [4-11] rather than the benefits of

\footnotetext{
* Correspondence: bhargavr@upstate.edu

'Upstate Medical University, 750, East Adams Street, Syracuse, NY 13210, USA Full list of author information is available at the end of the article
}

lowering serum phosphate per se, and have not addressed the fundamental questions of why, and to what target, serum phosphate should be controlled [12, 13]. Despite significant investment in expensive oral phosphate binders [14-19] (up to $\$ 4500$ per month per patient) [20], large pill burden (up to 15 pills daily) and significant rates of non-adherence [18], there remains no evidence that lowering serum phosphate definitely improves clinical outcomes.

Randomising subjects to a binder or placebo is unlikely to gain ethical approval for anything other than a short-term study, but we propose that a randomised 
controlled study of different concentrations of serum phosphate would answer the crucial questions around the value of controlling serum phosphate. However, whether it is possible to achieve and maintain low concentrations of serum phosphate in the range required to enable comparison with a higher concentration, and whether it is possible to maintain the phosphate concentration separation between the groups over an extended time period, is unknown. Furthermore, the consent rate for a trial in which subjects would be randomised to a treatment target above the current guidelines needs to be assessed.

We report the results of a study to examine these factors and to determine whether a large scale, long term randomized controlled outcome trial (RCT) may be possible. The Serum Phosphate Intervention in Renal Replacement Therapy (SPIRiT) trial randomised 104 hemodialysis patients to two groups with different serum phosphate target ranges; a Lower Range Group (LRG) and a Higher Range Group (HRG). Initial screening involved all patients from the two adult renal services of Greater Manchester in England, a conurbation with a total population of 2.8 million people.

\section{Methods}

All trial procedures adhered to the Declaration of Helsinki and the trial protocol was reviewed and approved by the National Regional Ethics Committee East Midlands Derby, REC Ref No. 13/EM/0042.

Details of the SPIRiT trial objectives, design and methods have been published previously [21]. It is an open-label, dual center, randomized controlled trial in which all hemodialysis patients from two large adult renal centers in Manchester (centers 1 and 2) had their electronic medical records screened. All in-center HD patients aged 30 years or above, on regular dialysis for at least 6 months (to ensure no recovery of renal function), meeting UK Renal Association standards for quality of dialysis, with a 3-month mean serum phosphate $>=1.4$ $\mathrm{mmol} / \mathrm{L}(4.3 \mathrm{mg} / \mathrm{dL})$ despite binders, serum PTH of < $900 \mathrm{pg} / \mathrm{L}$, and able to consent, were deemed eligible. All eligible subjects were approached for consent. Written Informed consent was obtained from subjects who agreed to enter the study and baseline characteristics recorded. Their current phosphate binder was discontinued and serum phosphate concentration checked after a 3 week washout period. The washout period ended if the phosphate concentration rose to $>=1.7 \mathrm{mmol} / \mathrm{L}(5.3$ $\mathrm{mg} / \mathrm{dL}$ ) but could continue for a maximum of 5 weeks. Those whose serum phosphate concentration did not reach $1.7 \mathrm{mmol} / \mathrm{L}(5.3 \mathrm{mg} / \mathrm{dL})$ were excluded from randomisation. All blood samples were collected before the commencement of a dialysis session (pre-dialysis samples). All subjects received a single dietetic review and advice regarding control of dietary phosphate intake.

\section{Randomization}

One-hundred and four dialysis patients were randomised in SPIRIT. It was anticipated that $70 \%$ of these would be recruited from study center 1 and its satellite centers, with the remaining 30\% from study center 2 and its satellite centers. A separate randomisation schedule was generated by the study statistician, using STATA (V12) statistical software - for each of the two study 'sites'. Only the study statistician had access to these, which were held on a password-protected drive on the central server at the University of Manchester.

To minimise imbalance in the number of patients allocated to either the lower phosphate range group or the upper phosphate range group, block randomisation was employed, using blocks of size 4 and 6 in a random order. Within each block, trial participants were randomly allocated to one or other of the groups with equal probability. As the trial was not blinded (both patients and the research team were not blind to group allocation, given the nature of the intervention), this strategy guarded against the research team being able to predict the next allocation in the sequence.

No formal sample size calculation has been conducted given the exploratory and evaluative nature of the study. The data analysis is largely descriptive and therefore the statistician was also not blinded to the intervention.

\section{Primary endpoint}

The percentage of study participants achieving, and being maintained within, the higher and lower target ranges for serum phosphate, over the duration of the maintenance phase of the study.

\section{Secondary endpoints}

1. Percentage of eligible invited participants willing to be randomised into a study which includes a "higher range' group.

2. Percentage of participants achieving consistent control of serum phosphate in each group over a 10 month maintenance period.

3. Drop-out rate from the study due to adverse events, kidney transplantation, inter-current illness, death. These numbers will inform the power calculation for the larger national study.

4. Pill burden per participant required to control serum phosphate.

5. Incidence of major vascular events, defined as nonfatal myocardial infarction or any cardiac death, any stroke, or any arterial revascularisation excluding 
dialysis access procedures (expected incidence of around 5\% per annum in patients on dialysis).

Randomisation was to the lower range group (LRG with treatment serum phosphate target of 0.8 to 1.4 $\mathrm{mmol} / \mathrm{L}-2.5-4.3 \mathrm{mg} / \mathrm{dL}$ ) or higher range group (HRG with treatment target of 1.8 to $2.4 \mathrm{mmol} / \mathrm{L}-5.6-7.4 \mathrm{mg} /$ $\mathrm{dL})$. The 'titration phase' comprised 2 months following randomization during which the subjects were prescribed variable doses of Lanthanum or Sevelamer (if necessary), in order to achieve study-group targets. Serum phosphate concentration was measured once a week during this phase with dose-adjustment of phosphate binder.

\section{Study medication}

Non-calcium containing phosphate binders were used since calcium containing binders could potentially confound the results because of differences in calcium load between the two groups [22]. Subjects had a choice between Lanthanum and Sevelamer and between tablet and granule preparations. Subjects could change from one formulation to another during the study if they felt unable or unwilling to take a particular formulation. The medication was supplied to them at their dialysis sessions, and advice regarding the change in dosage and change in the timing of the tablets was provided either in person, over the telephone or through the staff on the dialysis unit.

\section{Maintenance phase}

The maintenance phase started after the titration and lasted 10 months. The study conditions closely mirrored standard clinical care. Subjects had a pre-dialysis blood sample once a month for serum phosphate, calcium, albumin and cholesterol concentrations, and PTH measurements were performed every 3 months. The dose of phosphate binder was adjusted to maintain the serum phosphate in the target range of the study group. Each study visit coincided with their normal dialysis session and information regarding serious adverse events (SAE) was collected at the visit or by telephone. Study staff also sought additional information from hospital records and clinical staff regarding all reports of SAEs including myocardial infarction, stroke, death, other causes of hospital admission and fistula thrombosis.

\section{Statistical analysis}

A sample size calculation was not performed for this study given that its primary purpose was to assess issues of design of a larger study to establish whether phosphate concentrations influenced clinical outcomes. Therefore statistical analysis was descriptive or exploratory in nature, presenting appropriate summary statistics only (with 95\% confidence intervals where necessary). No inferential conclusions were drawn via reference to test statistics or $p$-values. Analyses were performed using STATA (v13) and Graphpad Prism Version 7.0.

Recruitment rates were calculated for the available hemodialysis population. Continuous demographic, health and blood-related variables were summarised using mean and standard deviation (SD) or median and inter-quartile range (IQR), dependent on their distribution. An exploratory Cox regression analysis was performed to calculate hazard ratios and their 95\% confidence intervals after adjusting for age, duration of dialysis, pre-randomization diabetes status and cardiovascular disease.

\section{Results}

\section{Randomization}

Fifty-one subjects were randomized to the HRG and 53 subjects to the LRG. Table 1 shows the baseline demographics and biochemistry. No stratification for known risk factors was employed because of the small numbers randomised, with the result that the LRG were 5 years older but had 0.5 years less dialysis vintage compared to the HRG. The HRG had a higher percentage of subjects with diabetes (29.4\% versus $20.8 \%)$, coronary artery disease $(29.4 \%$ versus $18.9 \%)$ and vascular disease $(31.4 \%$ versus $22.6 \%$ ) compared to the LRG. Statistical significance for baseline imbalance was not performed because of the small sample size.

\section{Primary end-point}

Primary end-point is the percentage of study participants achieving, and being maintained within, the higher and lower target ranges for phosphate, over the maintenance phase of the study [21]. Forty-seven subjects completed the titration phase in the HRG and 50 subjects in the LRG. At the end of titration, 29 HRG (61\%) and 19 LRG subjects (38\%) had achieved the target serum phosphate concentration, resulting in a mean phosphate of $2.00 \pm$ $0.4 \mathrm{mmol} / \mathrm{L}(6.2+/-1.2 \mathrm{mg} / \mathrm{dL})(\mathrm{HRG})$ and $1.63 \pm 0.4$ $\mathrm{mmol} / \mathrm{L}(5.0+/-1.2 \mathrm{mg} / \mathrm{dL})(\mathrm{LRG})(p<0.01)$.

Figure 1 shows the percentage of subjects achieving target serum phosphate concentrations at sequential time-periods after randomization.

At the start of washout, mean serum phosphate concentrations in the two groups was similar $-2.00+/-$ $0.42 \mathrm{mmol} / \mathrm{L}(6.2+/-1.3 \mathrm{mg} / \mathrm{dL})$ in the HRG versus 1.93 $+/-0.32 \mathrm{mmol} / \mathrm{L}(6.0+/-1.0 \mathrm{mg} / \mathrm{dL})$ in the LRG. Following the washout period and prior to randomization mean serum phosphate concentrations in the two groups were not different $(p=0.15)-2.1+/-0.36$ $\mathrm{mmol} / \mathrm{L}(6.5+/-1.1 \mathrm{mg} / \mathrm{dL})$ in HRG Vs $2.2 \mathrm{mmol} / \mathrm{L}+/-$ $0.4 \mathrm{mmol} / \mathrm{L}(6.8 \mathrm{mg} / \mathrm{dL}+/-1.2 \mathrm{mg} / \mathrm{dL})$ in the $\mathrm{LRG}$, but separated with a statistically significant difference at the 
Table 1 Baseline demographic features and laboratory measurements by treatment allocation

\begin{tabular}{|c|c|c|}
\hline & HRG & LRG \\
\hline Number randomised $(\mathrm{N})$ & 51 & 53 \\
\hline Age (years) (Median, IQR) & $60(48,70)$ & $65(54,71)$ \\
\hline \multicolumn{3}{|l|}{ Gender } \\
\hline Male: Female & $35: 16$ & $33: 20$ \\
\hline$\%$ of females: & $31.4 \%$ & $37.8 \%$ \\
\hline Diabetes: No Diabetes: & $15: 36$ & $11: 42$ \\
\hline Percentage with Diabetes: & $29.4 \%$ & $20.8 \%$ \\
\hline Previous CAD: & 15 & 10 \\
\hline No previous CAD: & 36 & 43 \\
\hline Percentage with CAD: & $29.4 \%$ & $18.9 \%$ \\
\hline Previous Vascular disease (including CAD): & 16 & 12 \\
\hline No Previous vascular disease: & 35 & 41 \\
\hline Percentage with previous vascular disease: & $31.4 \%$ & $22.6 \%$ \\
\hline $\begin{array}{l}\text { Duration on RRT: } \\
\text { (Median, IQR) }\end{array}$ & $\begin{array}{l}2.5 \text { years } \\
(1.5,5.0)\end{array}$ & $\begin{array}{l}2.0 \text { years } \\
(1.0,5.7)\end{array}$ \\
\hline $\begin{array}{l}\text { Serum Phosphate (Mean, SD) } \\
(P=0.1)\end{array}$ & $\begin{array}{l}2.09+/-0.4 \mathrm{mmol} / \mathrm{L} \\
(6.5+/-1.2 \mathrm{mg} / \mathrm{dL})\end{array}$ & $\begin{array}{l}2.2+/-0.4 \mathrm{mmol} / \mathrm{L} \\
(6.8+/-1.2 \mathrm{mg} / \mathrm{dL})\end{array}$ \\
\hline $\begin{array}{l}\text { Corrected calcium (Mean, SD) } \\
(P=0.4)\end{array}$ & $\begin{array}{l}2.37+/-0.4 \mathrm{mmol} / \mathrm{L} \\
9.5+/-1.2 \mathrm{mg} / \mathrm{dL}\end{array}$ & $\begin{array}{l}2.32+/-0.2 \mathrm{mmol} / / \mathrm{L} \\
9.3+/-0.8 \mathrm{mg} / \mathrm{dL}\end{array}$ \\
\hline $\begin{array}{l}\text { Serum PTH }(\mathrm{pg} / \mathrm{ml}) \\
\text { (Mean, SD) }(P=0.8)\end{array}$ & $418(273,571)$ & $392(174,675)$ \\
\hline $\begin{array}{l}\text { Serum Albumin }(g / L) \\
\text { (Mean, SD) }(P=0.2)\end{array}$ & $32.7+/-7.7$ & $34.6+/-6.9$ \\
\hline Serum Cholesterol (mmol/L) (Mean, SD) $(P=0.9)$ & $4.03+/-1.2$ & $4.08+/-1.6$ \\
\hline
\end{tabular}

end of titration, and maintained a separation of approximately $0.34 \mathrm{mmol} / \mathrm{L}(1.1 \mathrm{mg} / \mathrm{dL})$ throughout the maintenance phase (Fig. 2), despite a large range.

\section{Secondary end-points}

Seven hundred ninety-eight subject records were screened and 555 subjects excluded because they did not meet the screening criteria (Fig. 3). Fifty-three percent of the subjects approached gave consent (129/243). There was a difference in recruitment between the centers. Fifteen percent of the screened population was randomized at center $1(76 / 494)$ versus $9 \%$ at center $2(28 / 304)$. One hundred four subjects were randomized resulting in a recruitment rate of $13 \%$ of the dialysis population.

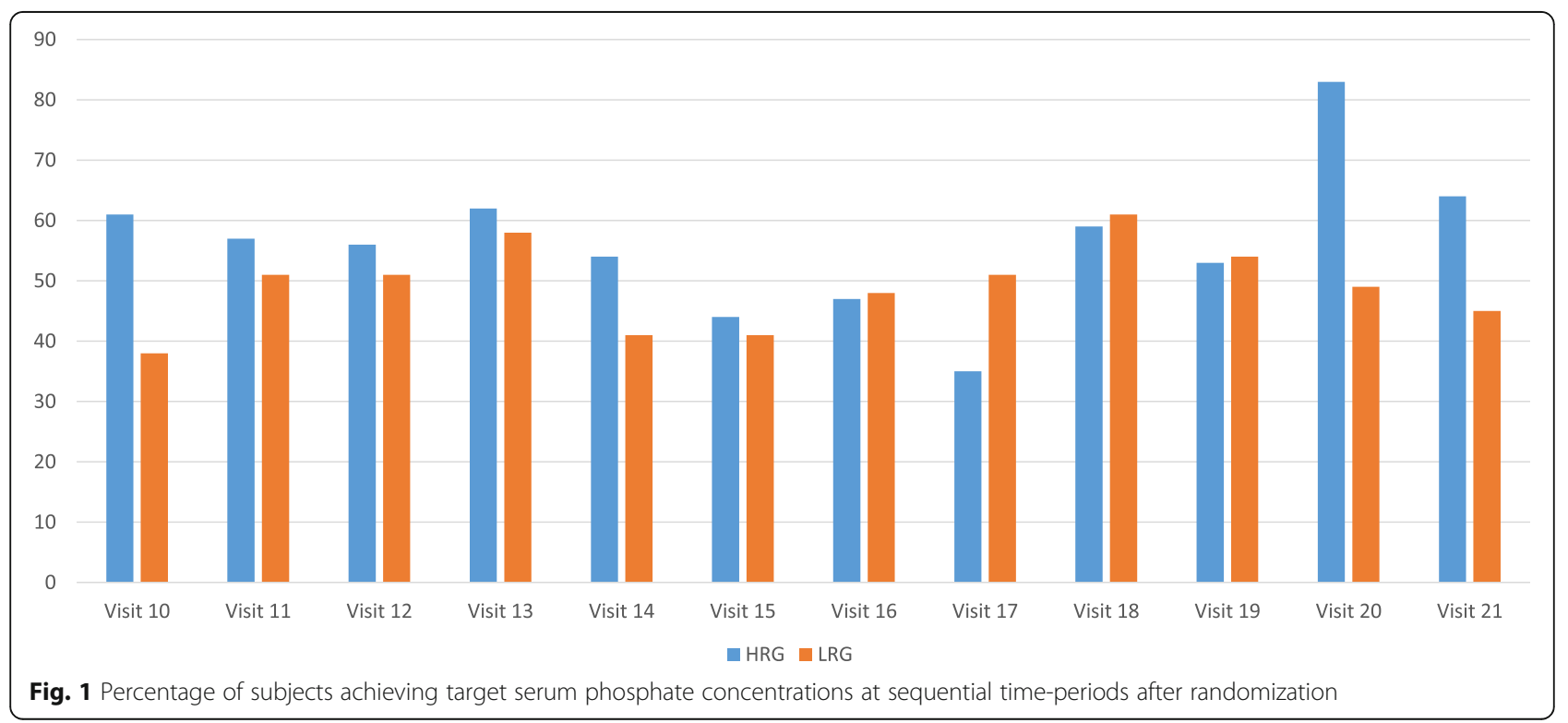




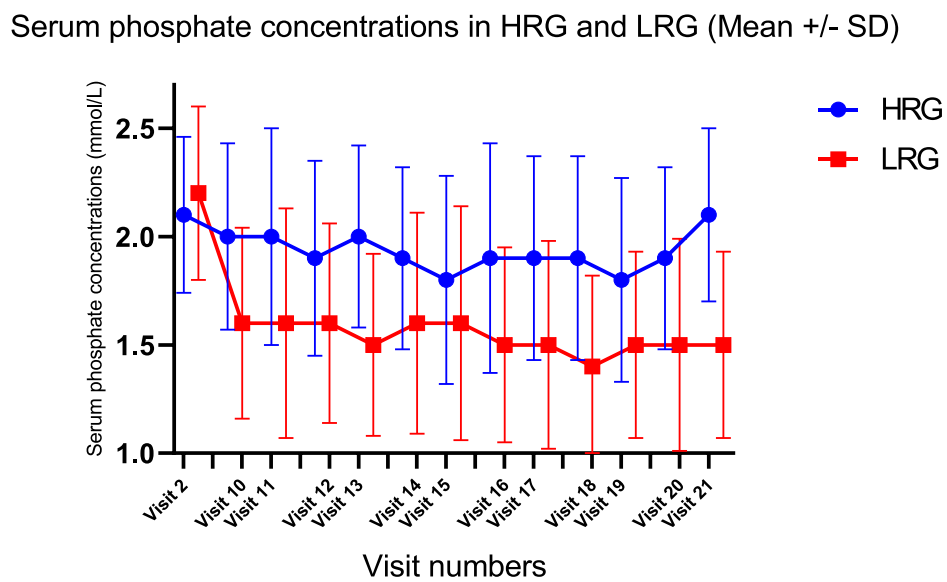

\begin{tabular}{|c|c|c|c|c|c|c|c|c|c|c|c|c|c|}
\hline & Visit 2 & Visit 10 & Visit 11 & Visit 12 & Visit 13 & Visit 14 & Visit 15 & Visit 16 & Visit 17 & Visit 18 & Visit 19 & Visit 20 & Visit 21 \\
\hline Significant? & No & Yes & Yes & Yes & Yes & Yes & No & Yes & Yes & Yes & Yes & Yes & Yes \\
\hline P value & 0. & $9<0.001$ & $<0.001$ & 0.00 & $3<0.001$ & 0.008 & 30.08 & $9<0.001$ & 0.002 & $2<0.001$ & 0.013 & 0.00 & $1<0.001$ \\
\hline Mean of HRG & & 1 & 22 & 1. & 9 & 1.9 & 1. & $\begin{array}{ll}8 & 1.9\end{array}$ & 1.9 & $\begin{array}{l}9 \\
7.9\end{array}$ & 1.8 & 1. & $\begin{array}{ll}9 & 2.1\end{array}$ \\
\hline Mean of LRG & & 2 & 1.6 & 1. & 1.5 & 1.6 & 1. & 1.5 & 1.5 & 1.4 & 1.5 & 1. & 1.5 \\
\hline Difference & & 1 & 0.4 & 0 & 0.5 & 0.3 & 0. & 0.4 & 0.4 & 0.5 & 0.3 & 0. & 0.6 \\
\hline HRG N & & 0 & 43 & 4 & 36 & 35 & 3 & 36 & 29 & 27 & 26 & 2 & 28 \\
\hline LRG N & & 1 & 40 & 4 & 39 & 39 & 4 & 38 & 31 & 35 & 33 & 3 & 32 \\
\hline
\end{tabular}

Fig. 2 Significant separation in the serum phosphate concentrations between HRG and LRG (mmol/L)

\section{Serious adverse events (SAEs)}

Seventy-two SAEs were reported. Elective hospital admissions, planned out-subject procedures, elective dialysis catheter exchanges, blood transfusions for renal anaemia, hospitalisation for kidney transplantation and dialysis related headaches were not considered SAEs. After review by the investigators, 63 SAEs were determined to be in accordance with the trial criteria (Table 2).

Nine deaths occurred in the HRG (17.6\%) and 2 in the LRG (3.8\%) - total mortality 11 (10.6\%) over the 12 months. SPIRiT was not powered to examine differences in outcomes between the two groups. However, exploratory survival analysis was performed in an attempt to control for covariates known to be associated with mortality, because of the 4-fold higher mortality in the HRG. Time to mortality and first SAE (mortality OR cardiovascular event OR thrombo-embolic event) were considered for this analysis. Due to the small number of subjects in the study, only the hazard ratio and $95 \%$ confidence interval are reported. The unadjusted hazard ratio (HR) for mortality in the LRG, compared to the HRG, was 0.2 (95\% CI $0.05,0.98)$. Cox regression analysis adjusting for age, duration of dialysis, diabetes and pre-existent vascular disease yielded an HR of 0.19 (95\% CI 0.04, 0.88) (Table 3).

\section{Trial drop-out}

The trial drop-out rate was $27 \%$ per annum with 65 subjects completing the full study - 35 LRG (66\%) and 30
HRG (58.8\%) (Table 4). More subjects withdrew consent in the LRG than in the HRG (9 versus 4). None of the subjects specified a reason for withdrawal of consent.

\section{Pill burden}

Subjects in the LRG took a median of 8 pills/sachets $(\mathrm{IQR}=3$ to 10$)$ a day of phosphate binders (Fig. 4). The maximum number of binders per day that any LRG subject took was 17 pills/sachets per day. Only one patient in the HRG was on 9 sevelamer pills per day for the duration of the study, which was the maximum number of binders per day for any HRG subject (Median = 1, IQR 0 to 3$)$.

\section{Alfacalcidol}

In the HRG, at Randomization (Visit 2), 33 patients were on alfacalcidol and 18 patients were not. No patients in this group stopped alfacalcidol during the duration of the study. There was no statistically significant difference in the mean serum phosphate levels or in the serum concentration of corrected calcium between these two groups at any visit (Fig. 5).

Table 5 shows the PTH concentrations in the HRG, in patients on alfa-calcidol and those who were not on alfa-calcidol. There was a significant difference in the median PTH between these patients $(P=0.07)$ at randomization but the difference disappeared as the study progressed. 


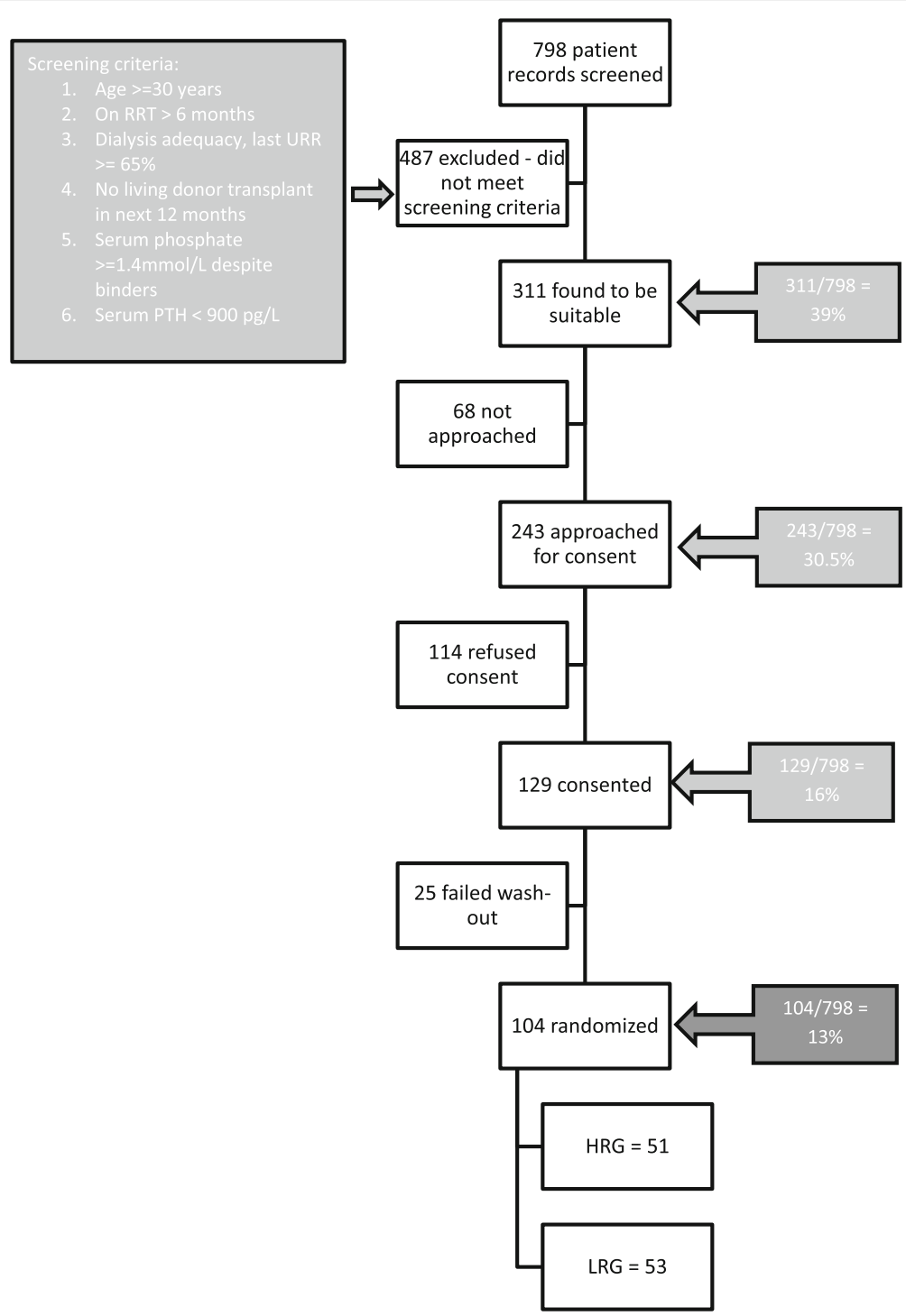

Fig. 3 Flowchart of patient screening and recruitment

In the LRG, 43 patients were on alfa-calcidol at randomization and 8 were not. Alfa-calcidol was stopped for one patient during the study because of hypercalcemia. There was no statistically significant difference in the mean serum phosphate levels or in the serum concentration of corrected calcium between the LRG patients on or off 1,25 alfa calcidol at any visit.

Table 6 shows the PTH concentrations in the LRG, in patients on alfa-calcidol and those who were not on alfa-calcidol. There was a significant difference in the median PTH between these patients $(P=0.002)$ at randomization but the difference could not be ascertained as the study progressed because there were only 8 patients not on alfa-calcidol.

The median weekly dosage of alfa-calcidol as $3 \mathrm{mcg}$ in both groups (IQR 1.6 to $3.5 \mathrm{mcg}$ in HRG and 1.8 to 3.5mcg in LRG) at randomization. There was no significant difference in the dosage between the two groups during the duration of the study.

\section{PTH and Cinacalcet}

Table 7 shows serum concentration of PTH in HRG and LRG for the duration of the study. There is no significant difference in the median PTH between the two groups at any point during the study. However, one patient was taking oral Cinacalcet $30 \mathrm{mg}$ a day at the start of the study - the patient continued with this dose for the study duration. Another patient in the HRG was started on Cinacalcit $30 \mathrm{mg}$ during the maintenance phase - this patient underwent a deceased donor kidney transplantation and exited the study after a month of starting the Cinacalcit. 
Table 2 Number of significant adverse events in both groups with description of the events

\begin{tabular}{|c|c|c|c|}
\hline Significant Adverse Events (SAEs) & Description of SAES & HRG & LRG \\
\hline \multirow[t]{4}{*}{ Cardiovascular events } & NSTEMI & 2 & 0 \\
\hline & CVA & 1 & 1 \\
\hline & Abdominal aortic aneurysm rupture & 0 & 1 \\
\hline & Total number of cardiovascular events & 3 & 2 \\
\hline \multirow[t]{3}{*}{ Thrombotic } & Fistula thrombosis & 5 & 3 \\
\hline & DVT and PE & 0 & 1 \\
\hline & Total number of thrombotic events & 5 & 4 \\
\hline Sepsis & & 17 & 10 \\
\hline Metabolic bone complication & & 1 & 1 \\
\hline \multirow[t]{9}{*}{ Miscellaneous } & Blood transfusion & 1 & 0 \\
\hline & Gastric ulcer & 1 & 0 \\
\hline & Skin lesions & 1 & 0 \\
\hline & Tumour & 1 & 1 \\
\hline & Transplant kidney pain & 0 & 1 \\
\hline & Sickle cell crisis & 0 & 1 \\
\hline & RTA with spinal injury & 0 & 1 \\
\hline & Non- cardiac & 0 & 1 \\
\hline & Total miscellaneous & 4 & 5 \\
\hline \multirow[t]{4}{*}{ Mortality } & Sepsis & 4 & 0 \\
\hline & Cardiovascular event & 3 & 1 \\
\hline & Sudden cardiac death & 2 & 1 \\
\hline & Total mortality & 9 & 2 \\
\hline Total SAEs & & 39 & 24 \\
\hline
\end{tabular}

\section{Compliance with study targets}

Four hundred thirteen blood samples were collected in the HRG during the maintenance period, i.e., visit 10 onwards. Individual patients' serum phosphate concentration varied quite widely, but considering all blood results collectively, $55 \%$ were within the treatment target range of 1.8 to $2.4 \mathrm{mmol} / \mathrm{L}$ ( 5.6 to $7.4 \mathrm{mg} / \mathrm{dL}$ ). Serum phosphate concentration was below the target in 134/413 samples and above the target in 55/413 blood samples. Only one patient remained within in the target range for the entire duration of the study.

Four hundred forty-nine blood samples were collected in the LRG during the maintenance period, i.e., visit 10 onwards. Forty-five percent of all serum phosphate results were within the treatment target range of 0.8 to
$1.4 \mathrm{mmol} / \mathrm{L}$ ( 2.4 to $4.3 \mathrm{mg} / \mathrm{dL}$ ). Serum phosphate concentration was below the target in 8/449 samples and above the target in 246/449 blood samples. Only two patients remained within the target range for the entire duration of the study.

\section{Other biochemical parameters}

Despite obtaining a clear separation in the serum concentration of phosphate levels between the two groups, mean serum calcium concentrations remained steady with no significant differences between the two groups (Fig. 6) - it remained steady at $2.3+/-0.2 \mathrm{mmol} / \mathrm{L}$ in both the groups. Serum albumin showed no significant difference between the two groups and the mean remained at $35+/-4 \mathrm{~g} / \mathrm{L}$ through the maintenance

Table 3 Adjusted and unadjusted hazard ratios

\begin{tabular}{llll}
\hline Outcome & Model & Hazard Ratio for LRG (vs. HRG) & 95\% Confidence Interval \\
\hline Death & Unadjusted & 0.21 & $0.05,0.98$ \\
& Adjusted $^{\mathrm{a}}$ & 0.19 & $0.04,0.88$ \\
Death + Cardiovascular Event & Unadjusted $^{*}$ & 0.34 & $0.13,0.87$ \\
& Adjusted $^{\mathrm{a}}$ & 0.33 & $0.13,0.86$
\end{tabular}

${ }^{a}$ Adjusted for: Age, Duration of Dialysis, Diabetes and Previous CAD/ Vascular Disease 
Table 4 Premature trial exits in both groups

\begin{tabular}{llll}
\hline Cause for trial-exit & Cause break-down & HRG & LRG \\
\hline Number randomized & & 51 & 4 \\
Successful transplant & & 0 & 4 \\
Transferred to home dialysis & Hospital admission till study-end & 2 & 0 \\
Withdrawn by study investigators & Intolerance to study medication & 1 & 0 \\
& High PTH at randomization & 1 & 0 \\
& Other reasons & 4 & 1 \\
Consent withdrawn by participant & Total & 0 & 6 \\
& Reason not given & 4 & 3 \\
Total pre-mature trial exits & 'too much going on', per patient & 4 & 1 \\
Mean duration in the study in months, SD & Total & 12 & 4.9 (3.9)
\end{tabular}

period. Serum Cholesterol dropped significantly ion the LRG from $4.1+/-0.9 \mathrm{mmol} / \mathrm{L}$ at randomization to 3.6 $+/-0.9 \mathrm{mmol} / \mathrm{L}$ at the end of titration. At the end of titration, mean cholesterol concentrations in the HRG had remained the same as that at randomization, 4.0 $+/-1 \mathrm{mmol} / \mathrm{L}$. Hence, at visit 10 , there was a statistically significant lowering of cholesterol in the LRG with $p<$ 0.04 . But the statistical significance did not persist beyond visit 10 .

\section{Discussion}

This study demonstrates that it is possible to recruit and randomize dialysis patients to two different serum phosphate concentrations, and maintain them over 10 months, despite the HRG being above the range recommended by current guidelines. Approximately 50\% of the SPIRiT subjects in either group achieved the trial target range of serum phosphate at multiple-time points in the trial and a difference of $1.1 \mathrm{mg} / \mathrm{dL}(0.34 \mathrm{mmol} / \mathrm{L})$ between the HRG and the LRG was achieved and maintained during the 10-month follow-up. Having two mutually exclusive target ranges rather than target concentrations ensured separation of the groups' mean phosphate values. Block and colleagues [3] studied retrospective data for 40,538 in-center hemodialysis subjects sampled from the Fresenius medical care North America patient statistical profile system, and stratified serum phosphate concentrations into 8 categories of $1 \mathrm{mg} / \mathrm{dL}$ increments. With multivariable adjustment, the relative risk of death increased from 1.0 for serum phosphate concentration of 4.0 to $5.0 \mathrm{mg} / \mathrm{dL}$ to $1.1,>1.2,1.4,1.7$ and 2.0 at serum phosphate concentrations of $5-6,6-7$,

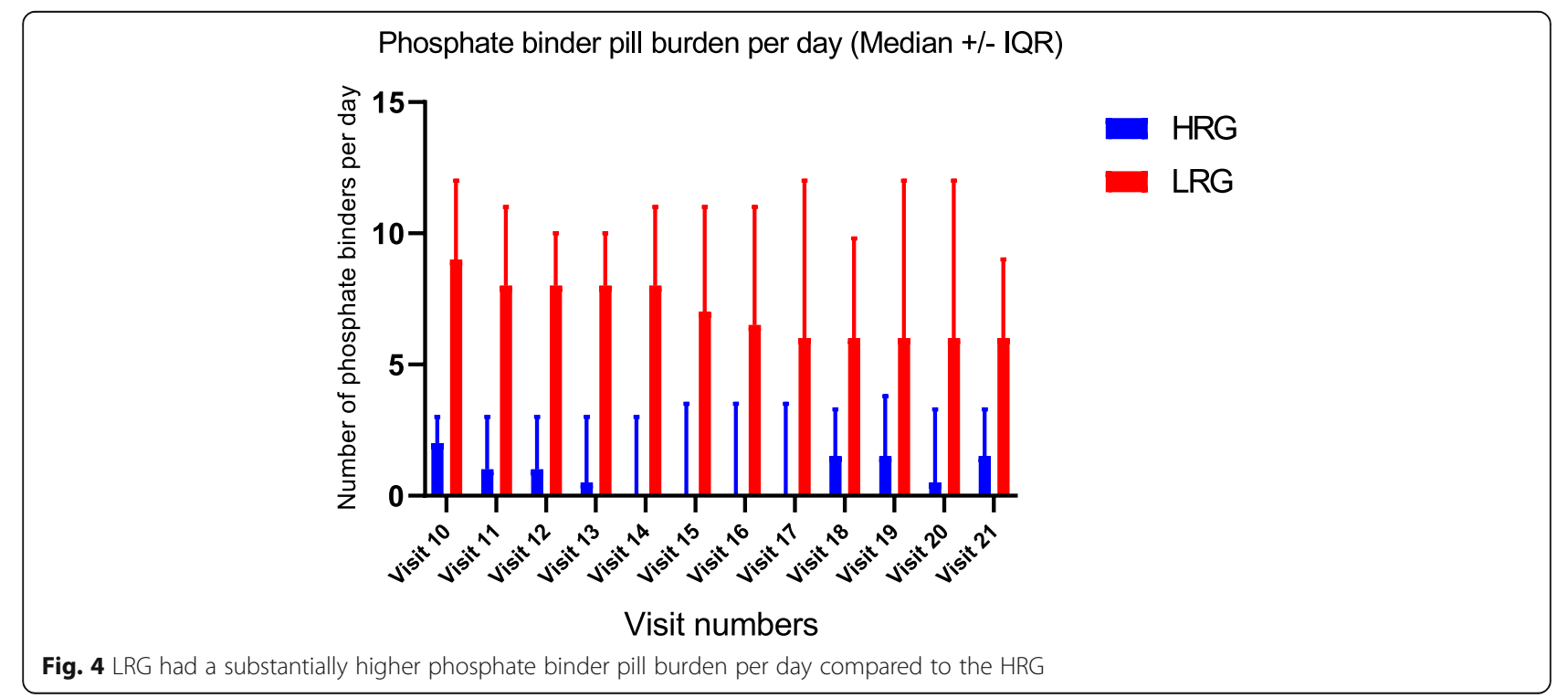




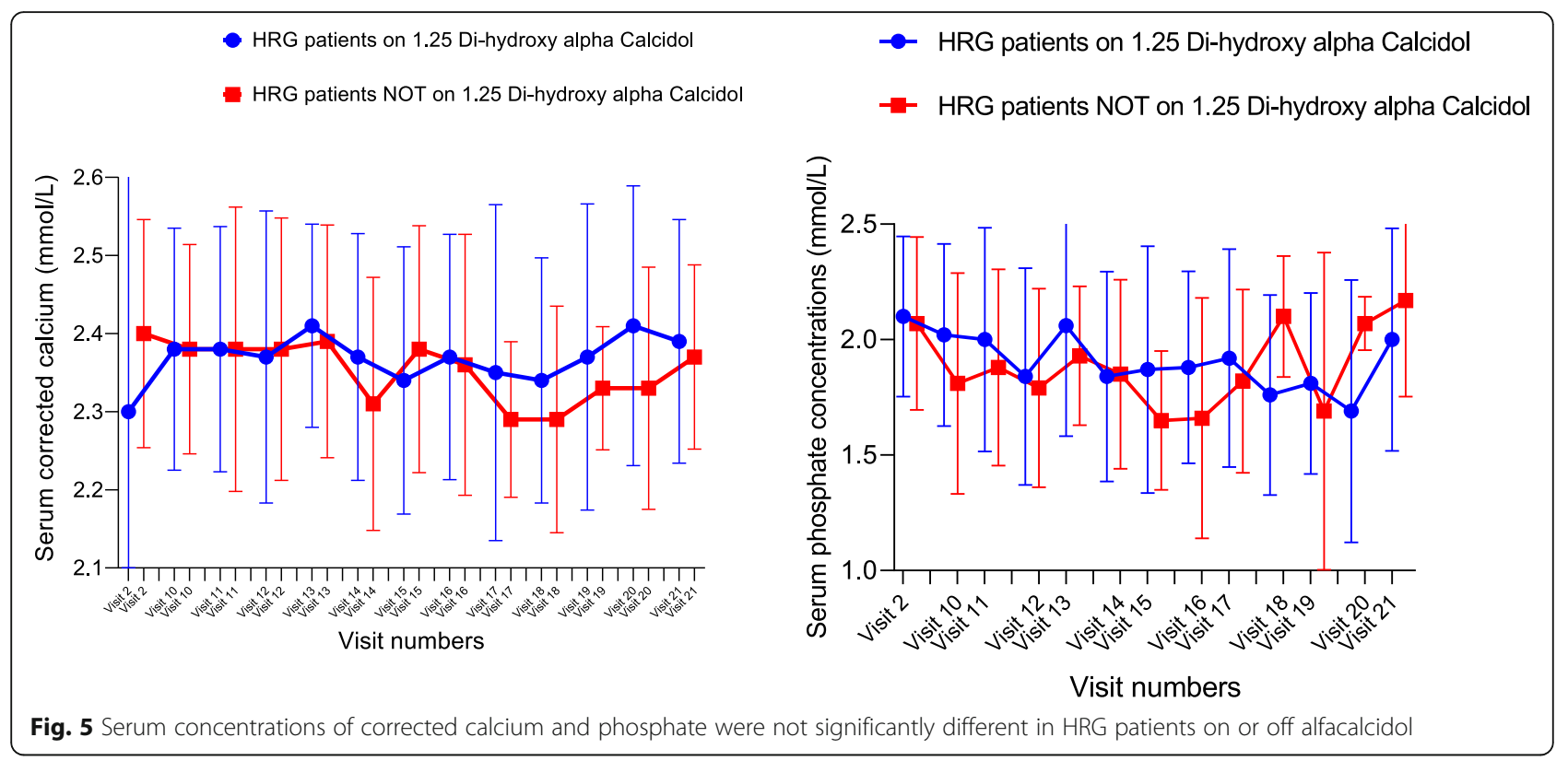

$7-8,8-9$ and $>9 \mathrm{mg} / \mathrm{dL}$ respectively. The phosphate separation achieved in the SPIRiT study was $0.34 \mathrm{mmol} / \mathrm{L}$ equivalent to $1.05 \mathrm{mg} / \mathrm{dL}$, and based on such retrospective data, would be adequate to show a difference in clinical outcomes, if any, in a large-scale RCT.

We did not achieve our goal of serum phosphate between 0.8 to $1.4 \mathrm{mmol} / \mathrm{L}(2.5-4.3 \mathrm{mg} / \mathrm{dL})$ as less than $1 /$ 2 subjects in that group achieved that goal and the mean level was $1.5+/-0.4 \mathrm{mmol} / \mathrm{L}(4.6+/-1.2 \mathrm{mg} / \mathrm{dL})$. We did achieve a difference between the 2 groups as the high phosphate group had a mean of $2.0+/-0.5 \mathrm{mmol} / \mathrm{L}$ $(6.2+/-1.5 \mathrm{mg} / \mathrm{dL})$ and still did not have a high percentage in the range. There was only one other study which attempted to randomize a similar number of patients to two different serum phosphate ranges [23]. This study was started after we started to recruit for the SPIRiT study, and had a much shorted follow-up period of 26 weeks. The investigators further used calcium carbonate,

Table 5 Serum PTH Concentrations in HRG patients on Alfaclacidol Versus HRG patients not on alfacalcidol

\begin{tabular}{llllll}
\hline HRG & Visit 2 & Visit 10 & Visit 13 & Visit 16 & Visit 19 \\
\hline Yes - Alfacalcidol & & & & & \\
25\% Percentile & 341 & 276 & 271.7 & 175.4 & 214.1 \\
Median & 512.5 & 416 & 429.7 & 474.3 & 512 \\
75\% Percentile & 827.5 & 676 & 693.2 & 752.6 & 842.1 \\
No - Alfacalcidol & & & & & \\
25\% Percentile & 67 & 77 & 39 & 90 & 108 \\
Median & 290 & 229 & 237 & 262 & 250 \\
$75 \%$ Percentile & 435 & 426 & 433 & 515 & 486 \\
P-value & 0.007 & 0.05 & 0.07 & 0.16 & 0.1 \\
\hline
\end{tabular}

a calcium containing phosphate binder. While it can be argued that there is no RCT evidence showing increased mortality in dialysis patients with calcium containing binders, there is evidence that they increase the risk of vascular calcification [24]. This is a compelling reason to not use these in the larger study. Further, there was no washout period which makes it possible that patients were included in the study who did not need to be on the phosphate binders in the first place.

Whilst it may be possible to achieve specific concentrations of phosphate over a specified time period, a larger study will depend on the willingness of physicians and patients to participate. Consequently, the secondary end points of this study examine this. Of the 22 local nephrologists, only 2 raised concerns regarding their patients taking part in the study, and this was not a clinical concern but related to the effect higher phosphate concentrations might have on their unit's adherence to

Table 6 Serum PTH concentrations in patients on alfa-calcidol and in those not on alfa-calcidol in LRG

\begin{tabular}{ccllll}
\hline & Visit 2 & 10 & 13 & 16 & 19 \\
\hline Yes - Alfacalcidol & & & & & \\
25\% Percentile & 217 & 213.5 & 240.5 & 164.7 & 231.4 \\
Median & 497 & 410 & 398 & 407.1 & 368 \\
75\% Percentile & 703 & 588.5 & 652.3 & 642.9 & 577 \\
No - Alfacalcidol & & & & & \\
25\% Percentile & 30 & 189 & 120.5 & 88.1 & 87.62 \\
Median & 109 & 260 & 239.5 & 269.3 & 254.3 \\
75\% Percentile & 302 & 277 & 299.1 & 427.2 & 482.9 \\
P-value & 0.002 & 0.29 & 0.1 & 0.3 & 0.4 \\
\hline
\end{tabular}


Table 7 Serum PTH concentrations in HRG and LRG during the study

\begin{tabular}{llllll}
\hline & Visit 2 & Visit 10 & Visit 13 & Visit 16 & Visit 19 \\
\hline HRG & & & & & \\
25\% IQR & 176 & 229 & 13 & 0 & 151 \\
Median & 359 & 406 & 202 & 166 & 440 \\
$75 \%$ IQR & 561 & 840 & 481 & 515 & 677 \\
$\quad$ Number of values & 46 & 39 & 31 & 29 & 18 \\
LRG & & & & & \\
25\% IQR & 121 & 189 & 138 & 102 & 257 \\
Median & 351 & 359 & 314 & 336 & 384 \\
$75 \%$ IQR & 632 & 534 & 467 & 532 & 575 \\
$\quad$ Number of values & 47 & 36 & 36 & 32 & 24 \\
P-value & 0.7 & 0.3 & 0.1 & 0.2 & 0.9 \\
\hline
\end{tabular}

national targets. They were anxious that a deterioration in reported results might attract criticism - an understandable concern in the current target-driven culture. They agreed to take part on condition that that year's UK Renal Registry report carried a comment about the possible effects of the SPIRiT study on compliance with targets.

Willingness of patients to participate, once approached, was high with 53\% (129/243) of the eligible participants consenting. Local research practices and trial personnel appear to have had a significant effect on recruitment with $16 \%$ of screened subjects at center 1 consenting versus $9 \%$ at center 2 . This was most likely due to the study clinician being primarily based at center 1. In a much larger study it is unlikely that the majority of centers would have a full time research clinician available and therefore the lower recruitment rate may be more representative of 'real life'. In addition, the pace of recruitment at the two centers varied $(8.4$ subjects per week recruited versus 4.3 per week respectively) probably for similar reasons.

At randomization, $29.4 \%$ of the HRG had diabetes versus $20.8 \%$ of the LRG. More HRG had previous coronary artery disease (29.4\% of HRG versus $18.9 \%$ of LRG) and more vascular disease (31.4\% HRG versus $22.6 \%$ LRG). We did not stratify for the cardiovascular risk factors at randomization because of the small sample size. In a larger study, it is likely that an adequate sample size will resolve these discrepancies. However, as the EVOLVE [25] study demonstrated, a large sample size may not always guard against bias, and the larger study would need stratified randomization for established cardiovascular risk factors in dialysis patients.

The overall trial drop-out rate of $27 \%$ per annum was comparable to other interventional RCTs in dialysis

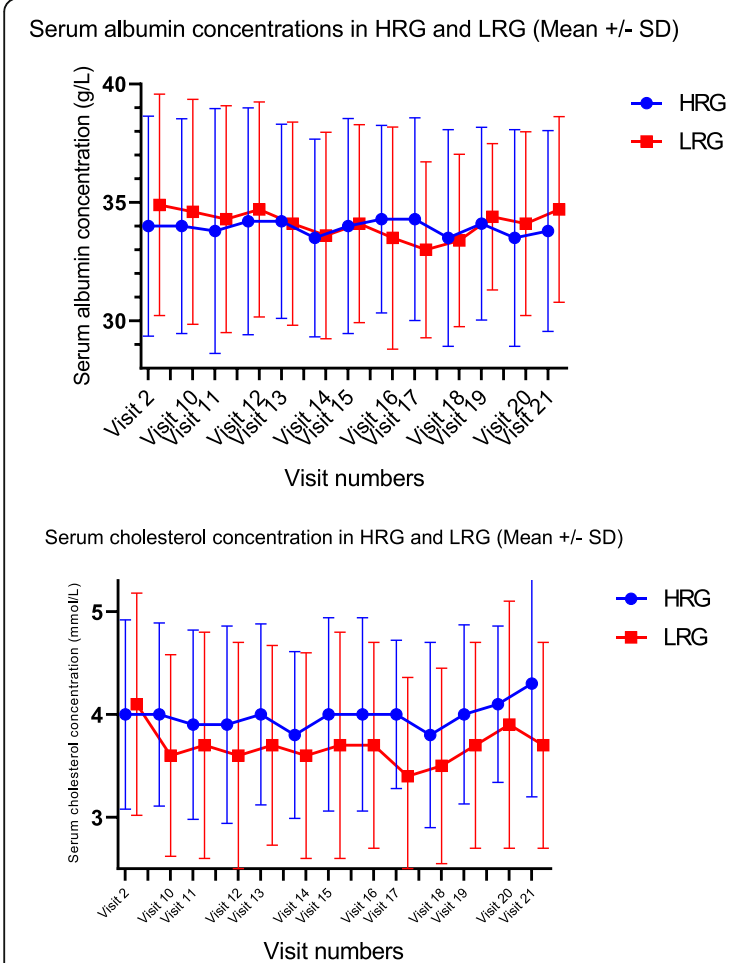

Fig. 6 Serum albumin, corrected calcium and cholesterol concentrations in the HRG and the LRG. Visit 2: Randomization visit, start of Titration to treatment targets for serum phosphate concentration Visit 10: 8 weeks after visit 2 - End of Titration. Visit 11 to Visit 21 are visits during the maintenance phase, each visit 4 weeks apart 
patients. The HEMO study randomized 1846 patients to high flux or low flux dialysis and followed them up for a mean of 2.84 years. Five hundred ninety patients dropped out over the course of the study which gives a drop-out of 33\% during the study [26]. On the other hand, the EVOLVE study randomized 3883 dialysis patients with secondary hyperparathyroidism to cinacalcet group or placebo with to examine differences in clinical outcomes. Seventy-eight percent of the subjects in the cinacalcet group and $61 \%$ in the control group stopped the study medication for non-protocol-specific reasons resulting in a crossover between the groups [27]. In the SPIRiT study, the drop-out rate in the LRG and HRG was $7 / 51(13 \%)$ and $10 / 53(19 \%)$ respectively. Consent withdrawal was higher in the LRG (4 vs 9). Although subjects did not give clear explanations for their withdrawal it seems likely that pill burden may have been a factor, with all LRG consent withdrawals happening in the first 4 months of the trial. Interestingly during the washout period at the start of the study 2 patients said they felt so much better having stopped their binders that they refused to restart and were withdrawn from the study.

Only non-calcium containing phosphate binders were used in this study, and at the start of the trial in 2013, availability was limited to lanthanum and sevelamer [13]. Any subject requiring high dose phosphate binders and intolerant of lanthanum was limited to sevelamer tablets which could result in a pill-burden of up to 15 tablets a day. Since the completion of this study, other non-calcium binders have become available which might make a larger study easier by providing subjects with more choice [28] and lower pill burden.

One patient in the HRG was on Cinacalcet $30 \mathrm{mg}$ a day at the start of the trial and stayed on it for the duration of the study. One other patient needed to be started on Cinacalcet during the study. Hypercalcemia was not a particular problem since only non-calcium containing phosphate binders were used. The dose of 1.25 alfa-calcidol was determined by the clinical care team and the presence or absence of alfa-calcidol therapy did not make an impact on the calcium and phosphate concentrations in the trial. However, the availability of alfa calcidol ensured that hypocalcaemia was adequately treated. With the availability of non-calcium containing phosphate binders, it is possible to deliver effective phosphate binding without the need for calcium loading; It is also possible to control PTH with calcimimetics despite a higher serum phosphate concentration - the availability of medication to address these mineral disorders in isolation makes it possible to design and conduct such studies.

Although mortality in the HRG (9/51) was substantially higher than in the LRG (2/53), the overall mortality for the study was $10.6 \%$, which compares favourably with the UK Renal Registry annual mortality rate of $11 \%$ [29]. A similar rate would be expected in a small trial such as this, with standard exclusion criteria possibly creating a selection bias towards subjects with fewer comorbidities. However, as the study progressed the difference in death rate between LRG and HRG increased noticeably, causing the Safety Monitoring Committee to scrutinise the data in ever greater detail each month. The Committee satisfied itself that the difference in mortality was likely to have occurred by chance plus the notable imbalance in risk factors at randomisation. Prevalence of diabetes, pre-existing coronary artery disease and vascular disease were significantly higher in the HRG. The trial was not powered to examine clinical outcomes such as mortality and cardiovascular events.

LRG and HRG achieved the treatment target ranges just about $50 \%$ of the time. Only 3 patients stayed in their respective target ranges for the entire duration of the study. A high pill burden which can enhance poor adherence is very likely the cause for the LRG patients not always achieving their target ranges. It is unclear why the serum phosphate concentrations were below the target range in the HRG over $30 \%$ of the time (134/ 413 samples in the maintenance period). This happened despite careful screening and washout ensuring that no patient who did not need a phosphate binder at baseline, was inadvertently recruited. One possibility is that the years of educating the dialysis staff and the patients about the benefit of low phosphate inadvertently introduced a bias where in the HRG patients practiced extra care about maintaining a low phosphate diet during the study period, since they were not on phosphate binders. In the design of the larger study, it is important to include a regular diet diary monitoring to see if patient and provider biases play a role in tighter phosphate control in the HRG.

Oral phosphate binder tablets can have significant gastro-intestinal side effects such as bloating which can lead to reduced oral intake and poor nutrition. We monitored serum albumin as a surrogate marker of nutrition, and did not find any significant reduction in the LRG which had the largest pill burden. As expected, the LRG had a lower serum cholesterol concentration (though not statistically significant). Sevelamer is a polymer which is known to cause a reduction in cholesterol levels.

Based on the results of this study it is possible to undertake a sample size calculation for a large scale, longer term, randomised controlled trial. The sample size calculation projects an annual incidence of $15 \%$ for the composite of non-fatal cardiovascular events and mortality in dialysis patients with $80 \%$ power to detect a $5 \%$ reduction in event rate. One thousand three hundred 
seventy-two patients will need to be randomized to give $80 \%$ power to detect a $5 \%$ reduction in event rate. To detect this difference, all patients would require to complete the trial. Allowing for trial attrition from reasons unrelated to the primary endpoint, the calculated sample size would need to be adjusted. For a 20\% non-primary end-point attrition, the sample size increases by $20 \%$ resulting in 1716 (858 per group).

\section{Conclusion}

This study demonstrates that it is possible to randomise dialysis patients to different concentrations of phosphate control - a hope first suggested in the introductory sections of guidelines published as long ago as 2003 (KDOQI) and 2009 (KDIGO). Though the TARGET study showed the possibility of randomization, SPIRiT study demonstrated that a clinically significant difference in serum phosphate concentrations can be maintained in the two groups over a prolonged period of time ( 1 year) which is necessary to study differences in clinical outcomes in the two groups. Both physicians and patients agreed to participate in numbers that suggest a larger scale study is possible. Despite this being an interventional RCT, $43 \%$ of the eligible target population were successfully consented, and the drop-out rate was comparable to published large scale, long-term dialysis studies. A clinically significant separation of mean serum phosphates was achieved between the groups representing a possible increased relative risk of 0.2 based on published observational data.

Whilst the number of deaths in the HRG was noticeably higher than in the LRG the study is under-powered to evaluate this outcome.

These results suggest that a similar but larger 2 year study is indeed possible. Based on a lower conversion rate of $10 \%$ from screening to randomisation, screening of 17,160 patients would be expected to result in 1716 consents; 858 patients in each group. One thousand two hundred fifty-three patients would remain after 12 months and approximately 915 in follow-up after 24 months. Such a study would counter "the lack of patient-centered outcomes as end points in the majority of trials in this field" as highlighted by KDIGO.

\section{Acknowledgements}

We are very grateful to NIHR-CLAHRC, NIHR-RfPB and 'Kidneys for life' this research. We are most grateful to all our collaborators and senior colleagues (Prof David Goldsmith, Dr. Martin Rutter, Dr. Rosie Donne, Dr. Grahame Wood, Dr. Anand Vardhan, and Prof Steve Roberts) who have kindly given their time to be on steering and safety monitoring committees to enable the conduct of this trial. We are very grateful to all our colleagues in the departments of renal medicine at the Manchester Hospitals NHS foundation trust and at Salford Royal Hospitals NHS Foundation Trust for facilitating this trial.

\section{Funding}

The study was funded by the UK National Institute of Health research (NIHR) - Research for Subject Benefit (RfPB) (Grant no. PB-PG-0711-25112). The trial registration number is ISRCTN24741445. The funding body had no role in the in the design of the study, collection, analysis, interpretation of the data and the writing of the manuscript.

\section{Availability of data and materials}

The datasets used and/or analysed during the current study are available from the corresponding author on reasonable request.

\section{Authors' contributions}

RB was the research fellow and the study clinician at one of the study sites. She was involved in the development of the study proposal, is a coapplicant for the grants, prepared the study documents including protocol, ethics and institutional approval paperwork. She screened patients, recruited, managed study medication dosing, data collection, data analysis and presentation. PAK is the PI at one of the study sites; he provided advice and input during the study set up and conduct of the study. He provided assistance with data analysis and presentation. He has reviewed the manuscript and suggested valuable changes which have all been incorporated. $\mathrm{MH}$ is the study Statistician. He performed the randomization and assisted with the data analysis. PB is the Director of Renal Research Labs and the custodian for all the study blood samples and study data. He was involved in the study design, assisted with study conduct and in data analysis. He has reviewed the manuscript and suggested valuable changes which have all been incorporated. $\mathrm{HH}$ organised the Kidney patient group for development of the study idea; she organised two-monthly meetings and kept minutes, and assisted with study design. She has reviewed the manuscript and suggested valuable changes which have all been incorporated. AJH is the $\mathrm{Cl}$ of the study. He developed the study design and is the primary applicant on the grant application. He was granted the NIHR-CLARHC grant which enabled him to take 6 weeks out of clinical commitments to write the NIHR-RfPB grant proposal. After successfully obtaining the grant, he supervised the research fellow during the conduct of the study and was the PI at one of the study sites. He constituted the trial steering and the safety monitoring committees and presented data periodically to these committees. He is closely involved with data analysis and presentation. He has been instrumental in getting the manuscript to the point of publication. All authors have read and approved the manuscript.

\section{Ethics approval and consent to participate}

All trial procedures adhered to the Declaration of Helsinki and the trial protocol was reviewed and approved by the National Regional Ethics Committee East Midlands Derby, REC Ref No. 13/EM/0042. Written informed consent was obtained from all participants.

\section{Consent for publication}

Not applicable.

\section{Competing interests}

Fifty percent of the study clinician's salary was funded by an unrestricted educational grant from Shire pharmaceuticals. Prof Alastair J Hutchison and Prof Philip Kalra have been on the advisory committees for Shire pharmaceuticals and Amgen and heave been recipients of unrestricted research grants from these parties on different occasions. None of these companies had any input into the design or conduct of the trial. The results presented in this paper have not been published previously in whole or part, except in abstract format.

\section{Publisher's Note}

Springer Nature remains neutral with regard to jurisdictional claims in published maps and institutional affiliations.

\section{Author details}

1Upstate Medical University, 750, East Adams Street, Syracuse, NY 13210, USA. ${ }^{2}$ Salford Royal Hospitals NHS Foundation Trust, Stott Lane, Salford, UK. ${ }^{3}$ University of Manchester, Oxford Road, Manchester M13 9WL, UK.

${ }^{4}$ Manchester Institute of Nephrology and Transplantation, Oxford Road, Manchester M13 9WL, UK. ${ }^{5}$ Manchester Academic Health Science Center, Manchester, UK. ${ }^{6}$ Dorset County Hospital, Dorchester, UK. 
Received: 10 April 2018 Accepted: 17 January 2019

Published online: 04 February 2019

\section{References}

1. Ganesh SK, Stack AG, Levin NW, Hulbert-Shearon T, Port FK. Association of elevated serum $\mathrm{PO}(4), \mathrm{Ca} \times \mathrm{PO}(4)$ product, and parathyroid hormone with cardiac mortality risk in chronic hemodialysis patients. J Am Soc Nephrol. 2001;12:2131-8.

2. Block GA, Hulbert-Shearon TE, Levin NW, Port FK. Association of serum phosphorus and calcium $\mathrm{x}$ phosphate product with mortality risk in chronic hemodialysis patients: a national study. Am J Kidney Dis. 1998:31:607-17.

3. Block GA, Klassen PS, Lazarus JM, Ofsthun N, Lowrie EG, Chertow GM. Mineral metabolism, mortality, and morbidity in maintenance hemodialysis. J Am Soc Nephrol. 2004;15:2208-18.

4. Lenglet A, Liabeuf S, El EN, Brisset S, Mansour J, Lemaire-Hurtel AS, et al. Efficacy and safety of nicotinamide in haemodialysis patients: the NICOREN study. Nephrol Dial Transplant. 2016;32:870.

5. Floege J, Covic AC, Ketteler M, Rastogi A, Chong EM, Gaillard S, et al. A phase III study of the efficacy and safety of a novel iron-based phosphate binder in dialysis patients. Kidney Int. 2014;86:638-47.

6. de Francisco AL, Leidig M, Covic AC, Ketteler M, Benedyk-Lorens E, Mircescu $\mathrm{GM}$, et al. Evaluation of calcium acetate/magnesium carbonate as a phosphate binder compared with sevelamer hydrochloride in haemodialysis patients: a controlled randomized study (CALMAG study) assessing efficacy and tolerability. Nephrol Dial Transplant. 2010;25:3707-17.

7. Hutchison AJ, Gill M, Copley JB, Poole L, Wilson RJ. Lanthanum carbonate versus placebo for management of hyperphosphatemia in patients undergoing peritoneal dialysis: a subgroup analysis of a phase 2 randomized controlled study of dialysis patients. BMC Nephrol. 2013;14:40.

8. Hutchison AJ, Laville M. Switching to lanthanum carbonate monotherapy provides effective phosphate control with a low tablet burden. Nephrol Dial Transplant. 2008:23:3677-84.

9. Hutchison AJ, Maes B, Vanwalleghem J, Asmus G, Mohamed E, Schmieder R, et al. Long-term efficacy and tolerability of lanthanum carbonate: results from a 3-year study. Nephron Clin Pract. 2006;102:c61-71.

10. Hutchison AJ, Maes B, Vanwalleghem J, Asmus G, Mohamed E, Schmieder R, et al. Efficacy, tolerability, and safety of lanthanum carbonate in hyperphosphatemia: a 6-month, randomized, comparative trial versus calcium carbonate. Nephron Clin Pract. 2005;100:c8-19.

11. Hutchison AJ, Speake M, Al-Baaj F. Reducing high phosphate levels in patients with chronic renal failure undergoing dialysis: a 4-week, dosefinding, open-label study with lanthanum carbonate. Nephrol Dial Transplant. 2004;19:1902-6.

12. Hutchison AJ. Novel phosphate binders: plus ca change, plus c'est la meme chose. Kidney Int. 2014;86:471-4.

13. Hutchison AJ, Smith CP, Brenchley PE. Pharmacology, efficacy and safety of oral phosphate binders. Nat Rev Nephrol. 2011;7:578-89.

14. Park H, Rascati KL, Keith MS. Managing oral phosphate binder medication expenditures within the Medicare bundled end-stage renal disease prospective payment system: economic implications for large U.S. dialysis organizations. J Manag Care Spec Pharm. 2015;21:507-14.

15. Ramakrishnan K, Braunhofer P, Newsome B, Lubeck D, Wang S, Deuson J, et al. The economic impact of improving phosphate binder therapy adherence and attainment of guideline phosphorus goals in hemodialysis patients: a Medicare cost-offset model. Adv Ther. 2014;31: 1272-86.

16. Keith MS, Wilson RJ, Preston P, Copley JB. Cost-minimization analysis of lanthanum carbonate versus sevelamer hydrochloride in US patients with end-stage renal disease. Clin Ther. 2014;36:1276-86

17. Ossareh S. Clinical and economic aspects of sevelamer therapy in end-stage renal disease patients. Int J Nephrol Renov Dis. 2014;7:161-8.

18. Fissell RB, Karaboyas A, Bieber BA, Sen A, Li Y, Lopes AA, et al. Phosphate binder pill burden, patient-reported non-adherence, and mineral bone disorder markers: findings from the DOPPS. Hemodial Int. 2016;20:38-49.

19. Wang S, Anum EA, Ramakrishnan K, Alfieri T, Braunhofer P, Newsome B. Reasons for phosphate binder discontinuation vary by binder type. J Ren Nutr. 2014:24:105-9.

20. Robison R, Cooney D, Low MB, Desai N. Sevelamer carbonate and lanthanum usage evaluation and cost considerations at a veteran's affairs medical center. Hosp Pharm. 2016;51:312-9.
21. Bhargava R, Kalra PA, Brenchley P, Hurst H, Hutchison A. A study to inform the design of a national multicentre randomised controlled trial to evaluate if reducing serum phosphate to normal levels improves clinical outcomes including mortality, cardiovascular events, bone pain, or fracture in patients on dialysis. Int J Nephrol. 2015;2015:579434.

22. Jamal SA, Vandermeer B, Raggi P, Mendelssohn DC, Chatterley T, Dorgan M, et al. Effect of calcium-based versus non-calcium-based phosphate binders on mortality in patients with chronic kidney disease: an updated systematic review and meta-analysis. Lancet. 2013;382:1268-77.

23. Wald R, Rabbat CG, Girard L, Garg AX, Tennankore K, Tyrwhitt J, et al. Two phosphAte taRGets in end-stage renal disease trial (TARGET): a randomized controlled trial. Clin J Am Soc Nephrol. 2017;12:965-73.

24. Moe SM, Chertow GM. The case against calcium-based phosphate binders. Clin J Am Soc Nephrol. 2006;1:697-703

25. Parfrey PS, Block GA, Correa-Rotter R, Drueke TB, Floege J, Herzog CA, et al. Lessons learned from EVOLVE for planning of future randomized trials in patients on dialysis. Clin J Am Soc Nephrol. 2016;11:539-46.

26. Eknoyan G, Beck GJ, Cheung AK, Daugirdas JT, Greene T, Kusek JW, et al. Effect of dialysis dose and membrane flux in maintenance hemodialysis. $\mathrm{N}$ Engl J Med. 2002;347:2010-9.

27. Chertow GM, Block GA, Correa-Rotter R, Drueke TB, Floege J, Goodman WG, et al. Effect of cinacalcet on cardiovascular disease in patients undergoing dialysis. N Engl J Med. 2012;367:2482-94.

28. Shah HH, Hazzan AD, Fishbane S. Novel iron-based phosphate binders in patients with chronic kidney disease. Curr Opin Nephrol Hypertens. 2015;24:330-5.

29. Steenkamp R, Rao A, Fraser S. UK renal registry 18th annual report (December 2015) chapter 5: survival and causes of death in UK adult patients on renal replacement therapy in 2014: national and Centre-specific analyses. Nephron. 2016;132(Suppl 1):111-44.

\section{Ready to submit your research? Choose BMC and benefit from:}

- fast, convenient online submission

- thorough peer review by experienced researchers in your field

- rapid publication on acceptance

- support for research data, including large and complex data types

- gold Open Access which fosters wider collaboration and increased citations

- maximum visibility for your research: over $100 \mathrm{M}$ website views per year

At $\mathrm{BMC}$, research is always in progress.

Learn more biomedcentral.com/submissions 